NASA Technical Memorandum 103701

\title{
Prediction of Ice Shapes and Their Effect on Airfoil Performance
}

Jaiwon Shin

National Aeronautics and Space Administration

Lewis Research Center.

Cleveland, Ohio

Brian Berkowitz

Sverdrup Technology, Inc.

Lewis Research Center Group

Brook Park, Ohio

Hsun Chen and Tuncer Cebeci

California State University

Long Beach, California

Prepared for the

29th Aerospace Sciences Meeting

sponsored by the American Institute of Aeronautics and Astronautics

Reno, Nevada, January 7-10, 1991 
PREDICTION OF ICE SHAPES AND THEIR EFFECT ON AIRFOIL PERFORMANCE

\author{
Jaiwon Shin* \\ National Aeronautics and Space Administration \\ Lewis Research Center \\ Cleveland, Ohio 44135 \\ Brian Berkowitz† \\ Sverdrup Technology, Inc. \\ Lewis Research Center Group \\ Brook Park, Ohio 44142 \\ and \\ Hsun H. Chen ${ }^{\star \star}$ and Tuncer Cebecit† \\ Aerospace Engineering Department \\ Callfornia State University \\ Long Beach, California 90801
}

\title{
SUMMARY
}

Calculations of lice shapes and the resulting drag increases are presented for experimental data on a NACA 0012 alrfoil. They were made with a combination of LEWICE and interactive boundary-layer codes for a wide range of conditions which include alrspeed and temperature, the droplet size and liquid water content of the cloud, and the angle of attack of the airfoil. In all cases the calculated results account for the drag increase due to ice accretion and, in general, show good agreement with data.

\subsection{INTRODUCTION}

The prediction of ice shapes and the determination of their effect on lifting surfaces is a problem of central importance in aircraft design since ice accretion can adversely affect aerodynamic performance of alrcraft components. In recent years, research has been undertaken to improve understanding of the formation of the ice, its accretion and the consequences for aerodynamic performance. Reference I provides an overview of the analytical and experimental icing activities in progress and reference 2 a review of the progress on one element of the overall activity, namely the unprotected airfoil icing problem. The latter discusses the development and validation of computer codes which predict the buildup of ice on unprotected airfolls and the resulting degradation of aerodynamic performance due to ice accretion.

These state-of-the-art reviews show that a two-dimensional ice accretion code, LEWICE, developed in 1983 at the University of Dayton Research Institute (ref. 3) and later modified by Ruff (ref. 4), provides a basis for the determination of the ice buildup on the leading edge of airfolls, for both the glaze ice formed at temperatures slightly below freezing and at relatively high liquid water contents and high flight speeds and for the rime ice which occurs at

"Aerospace Engineer. Member AIAA.

tAircraft Icing Engineer.

* Assoclate Professor. Member AIAA.

tiprofessor and Chairman. AIAA fellow. 
low temperatures, low liquid water contents, and low flight speeds. The three major elements of this code are: (1) an inviscid panel code, (2) a water droplet trajectory model, and (3) an energy balance equation proposed by Messinger (ref. 5). The ice accretion is computed on the airfoil leading edge as a function of time with user specifled time intervals. At each given time, the inviscid flowfield is determined from the panel code so that trajectory and heat transfer calculations can be performed. As the ice accretion builds up, its shape may become rugged especially in the case of glaze ice which is characterized by horns, and a rough, irregular surface, and leads to higher aerodynamic losses unlike the rime ice. Surface irregularities of the ice shape, see for example figure 1, can lead to multiple stagnation points with subsequent numerical difficulties, including a breakdown of the trajectory calculations which are necessary to determine the spatial distribution of water droplets. The automated smoothing procedure of reference 6 overcomes this difficulty by reducing the amplitude of the surface irregularities without loss of important flow characteristics and usually allows the calculations to be performed for greater times than before, without the problems caused by multiple stagnation points.

In addition to the need to predict ice shapes accurately, it is important to determine the performance degradation of the airfoil due to icing. This can be achleved by two codes based on solutions of the Reynolds-averaged NavierStokes equations and their reduced forms. The Navier-Stokes method employs the ARC-2D code and has been developed for iced airfoils by Potapczuk (ref. 7) and the interactive boundary-layer method of Cebeci (ref. 8) combines the solutions of the inviscid and viscous flow equations with an interaction law based on the Hilbert integral. The latter method has been incorporated into the LEWICE code so that ice shapes and performance degradation of the airfoil can be predicted.

The present paper applies the combination of the modified LEWICE code (one with the smoothing procedure) and the interactive boundary-layer (IBL) method to predict ice shapes and their effect on airfoil performance. The following section presents a brief description of the interactive boundary-layer procedure. The results of section 3 allow comparison between calculated and measured ice shapes and the resulting drag increase for a NACA 0012 airfoil. The experimental data is due to Olsen, Shaw, and Newton (ref. 9) and were obtained in the NASA Icing Research Tunnel (IRT). The measurements were made over a large range of conditions which include airspeed and temperature, the droplet size and liquid water content of the cloud, and the angle of attack of the airfoil. The paper ends with a brief discussion of the implications of the results and a summary of the more important conclusions.

\section{NOMENCLATURE}
A damping-length constant
$C_{D} \quad$ drag coefficient
$C_{i j}$ interaction-coefficient matrix
$k_{s}$ equivalent sand-grain roughness 


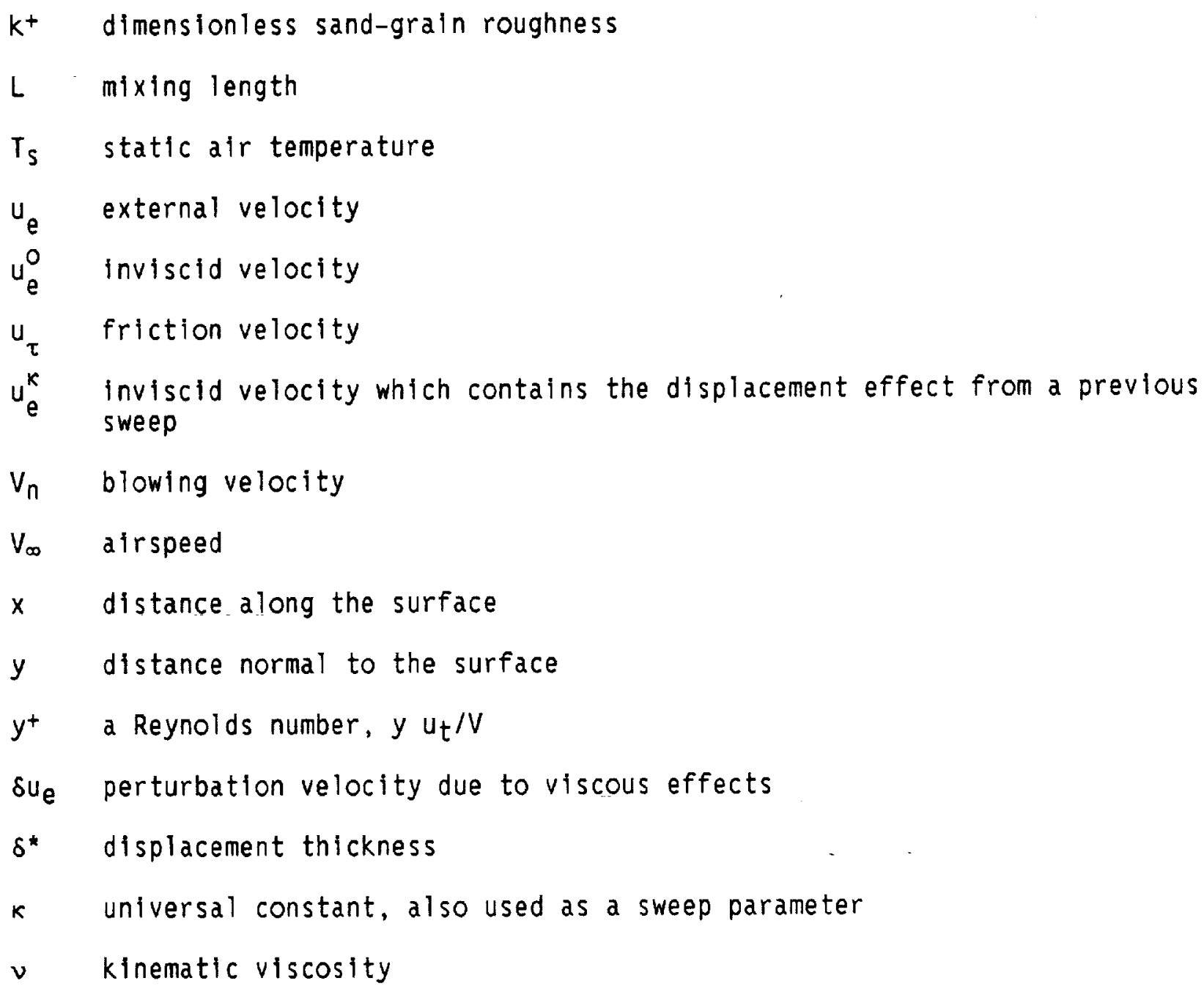

\subsection{DESCRIPTION OF THE INTERACTIVE BOUNDARY-LAYER METHOD}

The original LEWICE code is described in detail in reference 4 and an operator-free procedure incorporated into this code in order to avoid the occurrence of the multiple stagnation points caused by the formation of irregular surfaces on the ice shape is discussed in reference 6 . For this reason, the following description of the interactive boundary-layer procedure is brief. It couples the solutions of inviscid and viscous flow equations so as to ensure that each influences the other. The inviscid flow equations are solved by a panel method in which the airfoil and ice shapes are defined by a set of points where neighboring points are connected by straight-line panels which each have source density and vorticity. The vorticity strength of each panel is the same so that vorticity is defined by a total strength, adjusted to satisfy the Kutta condition. The source strengths have independent values on each panel and these are adjusted, by solving a set of simultaneous linear equations, to satisfy the normal-velocity boundary condition at the midpoints of the panels. In the strictly inviscid case this condition requires that the total normal velocity, freestream plus body sources and vortices, should vanish. When the boundary layer is simulated, the desired normal velocity, $v_{n}$, is finite and equals 
the derivative along the surface of the product of tangential velocity and displacement thickness, $d / d x\left(u_{e} \delta^{*}\right)$. It is known that this surface blowing distribution displaces the dividing streamline outward from the surface of the alrfoll to the location of the displacement thickness. Experience has shown that best results are obtained when surface pressures are calculated and the Kutta condition applied on the displacement surface rather than on the surface panels.

The boundary-layer equations for two-dimensional external steady incompressible flows are well known and are solved with the Reynolds shear stress term modeled with the Cebeci-Smith eddy-viscosity formulation (ref. 10$)$. For the external velocity distribution specified by the panel method, $u_{e}^{o}(x)$, and with su $x$ representing the perturbation velocity due to viscous effects, the edge bouhdary condition is written as

$$
u_{e}(x)=u_{e}^{0}(x)+\delta u_{e}(x)
$$

where, for the interaction region confined to the range $x_{a} \leq x \leq x_{b}$, which is often taken to include the airfoil chord length plus two chord lengths from the trailing edge,

$$
\delta u_{e}(x)=\frac{1}{\pi} \int_{x_{d}}^{x_{b}} \frac{d}{d \sigma}\left(u_{e} \delta^{*}\right) \frac{d \sigma}{x-\sigma}
$$

with $d\left(u_{e} \delta^{*}\right) / d \sigma$ corresponding to the blowing velocity.

In this form, equation (1) provides an outer boundary condition for the viscous-flow calculations which represents the viscous/inviscid interaction and can be generalized to the form

$$
u_{e}(x)=u_{e}^{k}(x)+\sum_{j=1}^{n} c_{i j}\left[\left(u_{e} \delta^{*}\right)_{j}-\left(u_{e} \delta^{*}\right)_{j}^{k}\right]
$$

where $u_{e}^{k}(x)$ corresponds to the inviscid velocity distribution which contains the displacement thickness effect, $\left(\delta^{*}\right)^{k}$, computed from a previous sweep. Here $c_{i j}$ denotes the interaction-coefficient matrix, which is obtained from a discrete approximation to the Hllbert integral.

Ice on airfolls can introduce substantial geometric changes to their leading edges in a short perlod and cause rapld varlations in the flow properties. As a result, the inviscid and viscous flow calculations may have difficulty in producing satlsfactory solutions. For the boundary-layer calculations, the iced airfoll is regarded as a smooth or a rough surface obtained by covering the leading-edge region with a "blanket" as shown in figure 2. It also makes use of a continuation method in which the initial calculations are performed for the smooth airfoll and subsequent ones for a serles of shapes that fall between the "smooth" and iced alrfolls. For each shape, the blowing velocity is computed from 


$$
v_{n}=\frac{d}{d x}\left[u_{e}\left(\delta^{*}-\delta\right)\right]
$$

where $\delta^{*}$ corresponds to the displacement thickness obtained from the boundary-layer solutions for the shape whose geometrical difference from the "smooth" airfoil is $\delta^{(f)}(x)$ and where the $\delta^{*}$-surface is outside the singularity surface. This allows the viscous effects to be incorporated into the inviscid flow solutions gradually, at each time step, thus reducing the sensitivity of the viscous flow solutions to the rapid changes in the pressure distribution near the leading edge. For further details, see reference 6 .

The numerical solutions of the boundary-layer equations, written in transformed variables, are obtained with the box method for both standard (prescribed pressure distribution) and interactive methods. This second-order finite-difference method has been used extensively by Cebeci and his associates for a wide range of flows (ref. 10). An inverse form of the equations is used to obtain the solutions with separation and the FLARE approximation, in which the convective term $u(\partial u / \partial x)$ is set equal to zero in the recirculating region, is employed. The nonlinear system of algebraic equations which results from the finite-difference approximations is Iinearized by Newton's method and solved by a block elimination procedure (ref. 10). It should be noted that the mixing length expression of the Cebeci-Smith model (ref. 8) has been modified to deal with surface roughness such as that associated with ice. This was done by modifying the mixing length and wall-damping expression, that is

$$
L=\kappa(y+\Delta y)\{1-\exp [-(y+\Delta y) / A]\}
$$

where $\Delta y$ is a function of an equivalent sand-grain roughness $k_{s}$. In terms of dimensionless quantities, with $k_{s}^{+}=k_{s}^{+} u_{\tau} / \nu$ and $\Delta y^{+}=\Delta y u_{\tau} / v$,

$$
\Delta y^{+}= \begin{cases}0.9\left[\sqrt{k_{s}^{+}}-k_{s}^{+} \exp \left(-k_{s}^{+} / 6\right)\right] & 5<k_{s}^{+} \leq 70 \\ 0.7\left(k_{s}^{+}\right)^{0.58} & 70 \leq k_{s}^{+} \leq 2000\end{cases}
$$

The equivalent sand-grain roughness for ice is determined from the expressions used in the LEWICE code, as discussed in the following section.

\subsection{RESULTS AND DISCUSSION}

The computer program described in reference 6 has the option of computing the flowfield without and with viscous effects. Studies conducted with this code show that the viscous effects do not have a pronounced effect on the prediction of ice shapes when the flowfleld is computed with the interactive boundary-layer procedure rather than with the inviscid method alone. Even though the viscous flowfield differs significantly from that computed with a panel method, especially near the leading edge, the computed shapes remain relatively unchanged because of the insensitivity of the current heat transfer model to viscous corrections. As a result, all ice shape calculations, presented herein, are performed with the inviscid panel method. 
Before we compare the calculated and measured results, it is useful to review the extensive data of 01 sen et al. (ref. 9) for a $0.53-\mathrm{m}$ chord NACA 0012 airfoil. The experimental data includes ice shapes and the resulting drag coefficients and were obtained over a range of air temperature, airspeed, airfoil angle of attack, spray time, liquid water content and droplet size. The data are very informative and helpful not only in understanding the ice structure and the way it forms, but it is also very useful in the development of computer codes such as the LEWICE and IBL codes to predict the ice accretion and resulting drag.

The experiments of 01 sen et al. encompass a temperature range that gives rise to both rime and $g l a z e$ ice. Figure $3(a)$ shows the repeatability of the ice shape and resulting drag coefficient for a typical rime ice shape accreted at $-26{ }^{\circ} \mathrm{C}$. Olsen et al. reported that the ice shapes and resulting drag coefficlents repeated quite well and the scatter in the drag coefficient was comparable to that observed with the clean airfoll data shown in figure 4.

Figure $3(b)$, corresponds to a different icing condition and the rime ice shape and drag coefficlent, $C_{D}$, again repeated well. The variations for both sets of $C_{D}$ data were about \pm 5 percent, which was close to the variation noted for the clean airfoll data.

Simflar comparisons are shown in figures $5(a)$ and (b) for two glaze ice shapes reported in reference 9 . As can be seen, there is a much larger variation in the ice shapes and drag coefficient for two cases on figure $5(a)$ and one case on figure $5(b)$. The variations for both sets of $C_{D}$ data are about \pm 1.5 percent of the average values of $C_{D}$ which is larger than those for the rime shapes or for the clean airfoll. Poor repeatability has also been noted in other airfoil tests with glaze ice. Olsen et al. stated that "no certain explanation for the poor repeatability of glaze ice shapes is available at this time."

The heat transfer model used in the LEWICE code makes use of an equivalent sand-grain roughness, $k_{s}$, expressed as a function of liquid water content ( $L W C$ ), static air temperature $\left(T_{S}\right)$, and airspeed $\left(V_{\infty}\right)$ in order to determine the ice shapes. With $c$ denoting the airfoil chord and $\left(k_{s} / c\right)$ base $=0.001177$, it is expressed in the following form

$$
k_{s}=\left[\frac{k_{s} / c}{\left(k_{s} / c\right)_{\text {base }}}\right]_{L W C} \cdot\left[\frac{k_{s} / c}{\left(k_{s} / c\right)_{\text {base }}}\right]_{T_{s}} \cdot\left[\frac{k_{s} / c}{\left(k_{s} / c\right)_{\text {base }}}\right]_{V_{\infty}}\left(\frac{k_{s}}{c}\right)_{\text {base }} \cdot c
$$

where each sand-grain roughness parameter is given by

$$
\begin{gathered}
{\left[\frac{k_{s} / c}{\left(k_{s} / c\right)_{\text {base }}}\right]_{L W C}=0.5714+0.2457(L W C)+1.2571(L W C)^{2}} \\
{\left[\frac{k_{s} / c}{\left(k_{s} / c\right)_{\text {base }}}\right]_{T_{s}}=0.047 T_{s}-11.27}
\end{gathered}
$$




$$
\left[\frac{k_{s} / c}{\left(k_{s} / c\right)_{\text {base }}}\right]_{V_{\infty}}=0.4286+0.0044139 V_{\infty}
$$

These expressions are empirical, are based on experimental data reported in reference 4 and do not account for the effect of time on the ice roughness. The experimental data of Olsen et al. shows that, for the glaze ice condition, the roughness increases with time, rapidly at first then more slowly. Their data also shows that rime ice is never as rough as glaze ice.

The experimental data of 01 sen et al. was obtained at two airspeeds, $V_{\infty}$, corresponding to 58 and $94 \mathrm{~m} / \mathrm{s}$. The data shows that the roughness is nearly independent of $V_{\infty}$ of 58 and $94 \mathrm{~m} / \mathrm{s}$ and that the equivalent sand-grain roughness parameter $k_{s}$ is also a function of the median volume droplet (MVD) size, as well as a function of the parameters in equation (7). Based on these experimental observations, it is plausible to write equation (7) as

$$
\begin{aligned}
k_{s}=\left[\frac{k_{s} / c}{\left(k_{s} / c\right)_{\text {base }}}\right]_{L W C} \cdot\left[\frac{k_{s} / c}{\left(k_{s} / c\right)_{\text {base }}}\right]_{T_{s}} \cdot\left[\frac{k_{s} / c}{\left(k_{s} / c\right)_{\text {base }}}\right]_{V_{\infty}} \\
\cdot\left[\frac{k_{s} / c}{\left(k_{s} / c\right)_{\text {base }}}\right]_{M V D}\left(\frac{k_{s}}{c}\right)_{\text {base }} \cdot c
\end{aligned}
$$

with

$$
\left[\frac{\mathrm{k}_{\mathrm{s}} / \mathrm{c}}{\left(\mathrm{k}_{\mathrm{s}} / \mathrm{c}\right)_{\text {base }}}\right]_{M V D}= \begin{cases}1 & M V D \leq 20 \\ 1.667-0.0333 \mathrm{MVD} & \mathrm{MVD}>20\end{cases}
$$

Some numerical studies conducted with the LEWICE code showed that the calculated results agreed better with experiment if the roughness parameter for $V_{\infty}$ was taken as a constant 0.6839 corresponding to $V_{\infty}$ of $58 \mathrm{~m} / \mathrm{s}$. Therefore, all subsequent calculations were performed with this assumption.

An appropriate sand-grain roughness parameter $k_{s}$ is also required in the turbulence model in the IBL code in order to compute the boundary-layer development on the airfoll and in the wake. It is plausible to conjecture that this parameter, as in the heat transfer model, is a function of $L W C, V_{\infty}$, $T_{s}$ and MVD. For this reason, calculations with $k_{s}$ corresponding to that used for the heat transfer model, equation (9) were performed with the IBL code for an ice shape determined with the LEWICE code. As expected, the drag coefficients calculated from the wake velocity profiles indicated that the results were sensitive to the magnitude of the roughness parameter. Several calculations with the value of $k_{s}$ of equation (9) multiplied by a constant equal to 2 yielded the best agreement with experiment. As a result, all boundary-layer calculations in the IBL code used a roughness parameter, $\left(k_{s}\right)$ IBL, given by

$$
\left(k_{s}\right)_{I B L}=2\left(k_{s}\right) \mathrm{Eq} .(9)
$$


The following subsection presents the results for the ice shapes determined with the LEWICE code and obtained for a range of conditions which include $V_{\infty}$, $T_{s}$, MVD and LWC, all for a given angle of attach of $4^{\circ}$, and compares them with the measured shapes. As stated earlier, these calculations were performed with the flowfield computed with the inviscid panel code. Comparisons between the calculated and measured drag coefficients, again for a range of conditions as above plus the angle-of-attack effect, are presented in subsection 3.2. In this case, the flowfield calculations on the airfoil and in the wake were performed in an interactive manner for the given calculated ice shapes, as discussed in section 2.0 .

\subsection{Comparison Between Calculated and Measured Ice Shapes}

Calculations were performed with the LEWICE code in order to determine the effects of air temperature, $T_{s}$, liquid water content $L W C$ and droplet size on ice shapes for the experimental data of 01 sen et al. (ref. 9) The calculated and experimental results are shown by solid and dotted lines, respectively, in figures 6 to 12. Those shown in figures 6 and 7 indicate the effect of air temperature on the ice accretion and, In general, show promising agreement with data for two alrspeeds. At low temperatures, when the ice shapes correspond to rime ice, the comparison between calculated and measured ice shapes are good. Except for one case in each figure, the calculations were performed without numerical difficulties for the stated times of ice accretion in the experiments which were $8 \mathrm{~min}$ for those in figure 6 and $6.2 \mathrm{~min}$ was for those in figure 7 .

The results in figures 8 and 9 show the effect of liquid water content on ice shapes. Those in (a) and (b) of each figure are for values of LWC of 1.0 and 1.3, and are in good agreement with experiment although the ice shapes of (b) are not as good as those of (a). For higher values of LWC, figures $8(c)$ and $g(c)$, the agreement between measured and computed ice shapes worsens. The results are not unexpected because the correlations for the roughness parameter for LWC used in reference 4 are for a range of LWC up to $1.0 \mathrm{~g} / \mathrm{m}^{3}$. Furthermore, the experimental data of 01 sen et al. (see also fig. 10, taken from ref. 9) indlcate that, for values of LWC ranging from 1.0 to 2, the effect of LWC on the ice shape is negligible and this suggests that the roughness parameter for LWC should be nearly constant. The calculations for the highest value of LWC also indicate some numerical difficulties with solutions breaking down after ice accretion time of $6 \mathrm{~min}$, rather than the specified time of $8 \mathrm{~min}$. A better correlation may improve the predicted ice shapes and avoid numerical difficulties.

Figures 11 and 12 show the effect of droplet size on the ice shapes, again for two alrspeeds. These results are generally in good agreement with data and are much better than those which did not include equation (10) in the calculations.

\subsection{Drag Coefficients}

At first the calculations were performed to investigate the effects of droplet size, liquid water content, and air temperature on the total drag coefficients of the airfoll. The ice shape determined at an angle of attach of $4^{\circ}$ 
with the procedure described above was fixed in the calculations. Tables I to III show the results obtained in this manner.

Tables $I(a)$ and (b) show the effect of air temperature on drag coefficient for ice accretion times of 8 and $6.2 \mathrm{~min}$ for two airspeeds, respectively, together with the varlation of the equivalent sand-grain roughness parameter $k_{s}$ with temperature. Figure 13 shows the variation of the drag coefficient as a function of total air temperature and corresponds to the results of table I. As can be seen, at lower temperatures where the ice accretion leads to the formation of rime ice, the computed drag coefficients are lower than the measured ones but have the same constant level (around 0.013) as the experimental values (around 0.020 ). At higher temperatures, the calculated drag coefficient shows a dramatic increase followed by a sudden decrease. In general, the drag coefficients of those iced airfoils, which are of the glaze type, are in good agreement with experiment despite the breakdown of the IBL calculations at $T_{s}=2.6655 \mathrm{~K}$ in table $I(b)$. In this case, the calculations capture the increase in the drag coefficient but not the peak value which may correspond to stall or post-stall conditions.

Tables II(a) and (b) show the effect of liquid water content on drag coefficient. Except at the high values of LWC, the calculations are performed without numerical difficulties and lead to satisfactory results with experimental data. Perhaps, as indicated in subsection 3.1, the calculated drag coefficlents can be improved if the predicted ice shapes are brought into a better agreement with measured ones by improving the roughness correlations for LWC.

Tables III(a) and (b) show the effect of droplet size on drag coefficient, again for two airspeeds. The results in table III(a). contain relatively lower drag coefficients indicating smaller viscous effects. For the three values of the droplet size, the computed values are in reasonable agreement with experiment. The experimental drag coefficients of table III(b), on the other hand, are very large for values of MVD $\geq 20$, suggesting the existence of increased flow separation and stall and/or post-stall conditions. For these conditions, the computed values are in poor agreement with data.

Figures 14 and 15 show the variation of the drag coefficient of the airfoll with angle of attack for a given ice shape determined at $\alpha=4^{\circ}$. The results in figure 14 are for rime ice and indicate remarkably good agreement between calculations and experiment. The increase in the drag coefficient due to the ice is well represented and the turbulence model with equivalent sandgrain roughness parameters as given by equation 10 allows the calculations to follow the experimental trend.

The results in figure 15 correspond to glaze ice and are again in remarkably good agreement with experimental data except at higher angles of attack where the code broke down due to the occurrence of stall. It should be noted that the calculations were performed for the 1 ce shape with $L W C=1.3 \mathrm{~g} / \mathrm{m}^{3}$ rather than $2.1 \mathrm{~g} / \mathrm{m}^{3}$ since, according to figure 10 , the ice shapes are not sensitive to LWC. In figures 8 and 9 , it has already been shown that predicted ice shapes are not in good agreement with data at the higher values of LWC and indicates the need for improved roughness correlations. Since the accuracy of the drag coefficlent is a strong function of the ice shape, it is necessary to use a shape that fits the experimental data as well as possible. 


\subsection{CONCLUDING REMARKS}

The extensive results of the previous section show that the interactive boundary-layer method of section 2.0 and the modified LEWICE code provide a satisfactory basis for the calculation of ice shapes and their effect on airfoll performance. The results encompass a wide range of icing conditions and angles of attack of direct relevance to engineering practice so that the method provides a basis for extension to the representation of icing on wings, other lifting bodies and engine intakes.

Improvements can be made to the present approach, for example to the correlation for equivalent sand-grain roughness and to the representation of the drag coefficient when the ice accretion gives rise to stall or post-stall conditions. In the former case, additional measurements and calculations are required and in the latter a combination of local flow measurements and calculations to examine the sensitivity of the aerodynamic flow characteristics to the time-change in ice shapes. The improvements should be pursued but should not preclude the immediate extension of the calculation method to deal with three-dimensional lifting bodies and the development of a better heat transfer formulation so that the ice accretion model can also include the effects of surface heating on ice formation.

\subsection{REFERENCES}

1. Shaw, R.J., "NASA's Aircraft Icing Analysis Program," NASA TM-88791, 1987.

2. Shaw, R.J., Potapczuk, MC., and Bidwell, C.S., "Predictions of Airfoll Aerodynamic Performance Degradation Due to Ice," in Numerical and Physical Aspects of Aerodynamic Flow5, IV., T. Cebeci, ed., Springer-Verlag, 1990.

3. MacArthur, C.D., Keller, J.L., and Leurs, J.K., "Mathematical Modeling of Ice Accretion on Airfolls," AIAA-82-0284, 1982.

4. Ruff, G.A. and Berkowitz, B.M., "User's Manual for the NASA Lewis Ice Accretion Prediction Code (LEWICE)," NASA CR-185129, 1990.

5. Messinger, B.L., "Equilibrium Temperature of an Unheated Icing Surface as a Function of Airspeed," Journal of Aeronautical Science, Vol. 20, No. 1 , Jan. 1953, pp. 29-42.

6. Cebeci, T., Chen, H.H., and Alemdaroglu, N., "Fortified LEWICE with Viscous Effects," AIAA-90-0754, 1990, also to be published in Journal of Aircraft, 1991.

7. Potapczuk, M.G., "Navier-Stokes Analysis of Airfoils with Leading-Edge Ice Accretions," Ph.D. Dissertation. The University of Akron, May 1989.

8. Cebeci, T., "Calculation of Flow Over Iced Airfoil," AIAA Journal, Vol. 27, 1989 , p. 853.

9. Olsen, W., Shaw, R.J., and Newton, J., "Ice Shapes and the Resulting Drag Increase for a NACA 0012 Airfoil," NASA TM-83556, 1984. 
10. Bradshaw, P., Cebeci, T., and Whitelaw, J.H., Engineering Calculation Methods for Turbulent Flows, Academic Press, London, 1981.

TABLE I(a). - EFFECT OF AIR TEMPERATURE ON DRAG COEFFICIENT

[Droplet size, MVD, $20 \mu \mathrm{m}$.

(a) Airspeed, $V_{\infty}, 58 \mathrm{~m} / \mathrm{s}$; liquid water content, LWC, $1.3 \mathrm{~g} / \mathrm{m}^{3}$; ice accretion time, $8 \mathrm{~min}$

\begin{tabular}{|c|c|c|c|}
\hline $\begin{array}{c}\text { Static air } \\
\text { temperature, } \\
T_{S}, \\
K\end{array}$ & \multicolumn{2}{|c|}{ Drag coefficient, $C_{D}$} & $\begin{array}{c}\text { Equivalent } \\
\text { sand-grain } \\
\text { roughness, } \\
\mathrm{k}_{\text {S }}, \\
\mathrm{nmm}\end{array}$ \\
\cline { 2 - 4 } & Calculated & Experimental & \\
\hline 245.35 & 0.01279 & 0.01941 & 0.334 \\
253.35 & .01346 & .02161 & .815 \\
259.25 & .01431 & .02072 & 1.170 \\
266.45 & .05075 & .06036 & 1.602 \\
269.25 & .02873 & .02807 & 1.770 \\
270.35 & .02105 & .02647 & 1.837 \\
\hline
\end{tabular}

(b) Airspeed, $V_{\infty}, 94 \mathrm{~m} / \mathrm{s} ;$ Tiquid water content, LWC, $1.05 \mathrm{~g} / \mathrm{m}^{3}$; ice accretion time, $6.2 \mathrm{~min}$

\begin{tabular}{|c|c|c|c|}
\hline $\begin{array}{c}\text { Static air } \\
\text { temperature, } \\
T_{S} \text {, } \\
K\end{array}$ & \multicolumn{2}{|c|}{ Drag coefficient, $C_{D}$} & $\begin{array}{c}\text { Equivalent } \\
\text { sand-grain } \\
\text { roughness, } \\
\mathrm{k}_{\mathbf{S}}, \\
\mathrm{mm}\end{array}$ \\
\cline { 2 - 4 } & Calculated & Experimental & \\
\hline 242.65 & 0.01143 & 0.0238 & 0.126 \\
256.55 & .01300 & .0370 & .740 \\
260.95 & .04549 & .0606 & .934 \\
266.55 & $(\mathrm{a})$ & .0756 & 1.182 \\
\hline
\end{tabular}

a Breakdown.

TABLE II. - EFFECT OF LIQUID WATER CONTENT ON DRAG COEFFICIENT

[Droplet size, MVD, $20 \mu \mathrm{m}$; airspeed, $V_{\infty}$, $58 \mathrm{~m} / \mathrm{s}$; ice accretion time, $8 \mathrm{~min}.]^{\infty}$

(a) Static air temperature, $\mathrm{T}_{\mathrm{s}}, 253.35 \mathrm{~K}$

\begin{tabular}{|c|c|c|c|}
\hline \multirow{2}{*}{$\begin{array}{c}\text { Liquid water } \\
\text { content, } \\
\text { LWC, } \\
\mathrm{g} / \mathrm{m}^{3}\end{array}$} & \multicolumn{2}{|c|}{ Drag coefficient, $C_{D}$} & \multirow{2}{*}{$\begin{array}{c}\text { Equivalent } \\
\text { sand-grain } \\
\text { roughness, } \\
\mathrm{k}_{\mathrm{s}} \text {, } \\
\mathrm{mm}\end{array}$} \\
\hline & Calculated & Experimental & \\
\hline $\begin{array}{l}1.0 \\
1.3 \\
2.0\end{array}$ & $\begin{array}{c}0.01398 \\
.01346 \\
\text { (a) }\end{array}$ & $\begin{array}{r}0.0212 \\
.0246 \\
.0312\end{array}$ & $\begin{array}{r}0.561 \\
.815 \\
1.647\end{array}$ \\
\hline
\end{tabular}

(b) Static air temperature, $T_{S}, 263.48 \mathrm{~K}$

\begin{tabular}{|c|c|c|c|}
\hline $\begin{array}{c}\text { Liquid water } \\
\text { content, } \\
\text { LWC, } \\
\mathrm{g} / \mathrm{m}^{3}\end{array}$ & \multicolumn{2}{|c|}{ Drag coefficient, $C_{D}$} & $\begin{array}{c}\text { Equivalent } \\
\text { sand-grain } \\
\text { roughness, } \\
\mathrm{k}_{\mathrm{s}}, \\
\mathrm{mm}\end{array}$ \\
\cline { 2 - 4 } & Calculated & Experimental & 0.980 \\
1.0 & 0.02976 & 0.0262 & 1.424 \\
1.3 & .04585 & .0307 & 1.975 \\
1.6 & (a) & .0456 & \\
\hline
\end{tabular}

areakdown. 
TABLE III. - EFFECT OF DROPLET SIZE ON ORAG COEFFICIENT

(a) Airspeed, $V_{\infty}, 58 \mathrm{~m} / \mathrm{s}$; 1 iquid water content, LWC, $1.3 \mathrm{~g} / \mathrm{m}^{3}$; static air temperature, $T_{S}$.

\begin{tabular}{|c|c|c|c|}
\hline $\begin{array}{c}\text { Droplet } \\
\text { size, } \\
\text { MVD, } \\
\mu \mathrm{m}\end{array}$ & \multicolumn{2}{|c|}{ Drag coefficient, $C_{D}$} & $\begin{array}{c}\text { Equivalent } \\
\text { sand-grain } \\
\text { roughnes5, } \\
k_{5}, \\
\text { Calculated }\end{array}$ \\
\hline 14 & 0.01283 & 0.0121 & 0.334 \\
20 & .01279 & .0193 & .334 \\
26 & .01285 & .0196 & .268 \\
\hline
\end{tabular}

(b) Airspeed, $V_{n}, 94 \mathrm{~m} / \mathrm{s}$; liquid water content, LWC, $1.05 \mathrm{~g} / \mathrm{m}^{3}$; static air temperature, $T_{5}$, $260.95 \mathrm{~K}$; ice accretion time, $6.2 \mathrm{~min}$

\begin{tabular}{|c|c|c|c|}
\hline \multirow{2}{*}{$\begin{array}{c}\text { Oroplet } \\
\text { size, } \\
\text { MVD, } \\
\mu m\end{array}$} & \multicolumn{2}{|c|}{ Drag coefficient, $C_{D}$} & \multirow{2}{*}{$\begin{array}{c}\text { Equivalent } \\
\text { sand-grain } \\
\text { roughness, } \\
k_{s}, \\
\mathrm{~mm}\end{array}$} \\
\hline & Calculated & Experimental & \\
\hline $\begin{array}{l}14 \\
20 \\
26\end{array}$ & $\begin{array}{r}0.01578 \\
.04549 \\
.05356\end{array}$ & $\begin{array}{r}0.03090 \\
.09510 \\
.12660\end{array}$ & $\begin{array}{r}0.934 \\
.934 \\
.747\end{array}$ \\
\hline
\end{tabular}

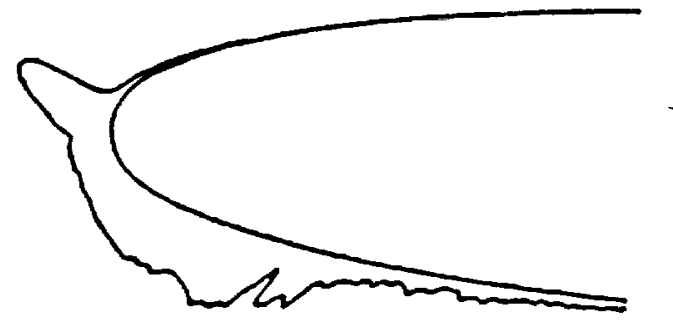

Fig. 1. Fxample of real ice arcretion from Ref. 3

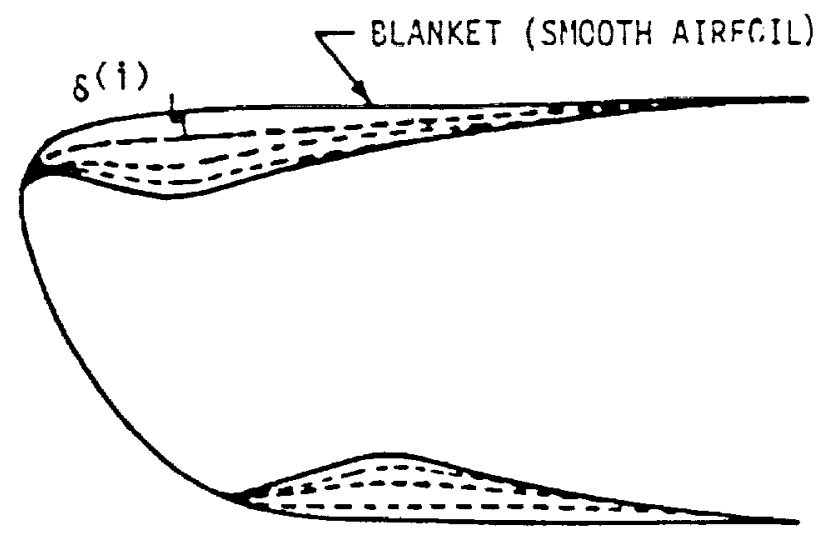

Fig. 2. Boundary-layer model used in the viscousflow calculations. 

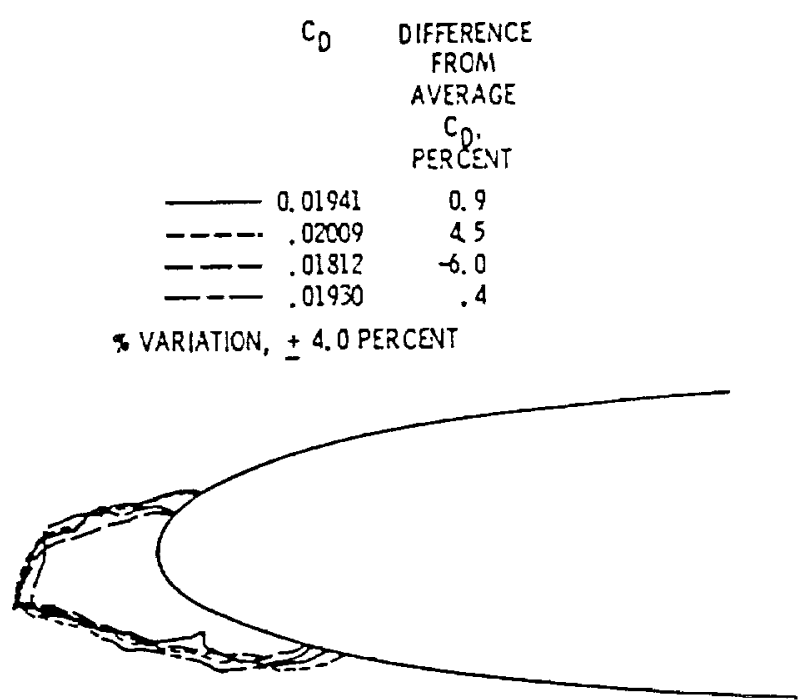

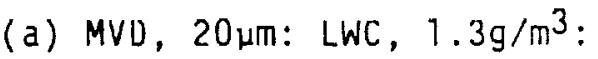
time, 8 min.

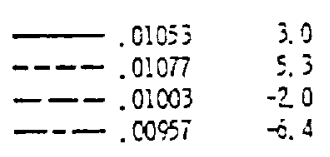

: VARIATIICN, \pm 5. OPERCEVT

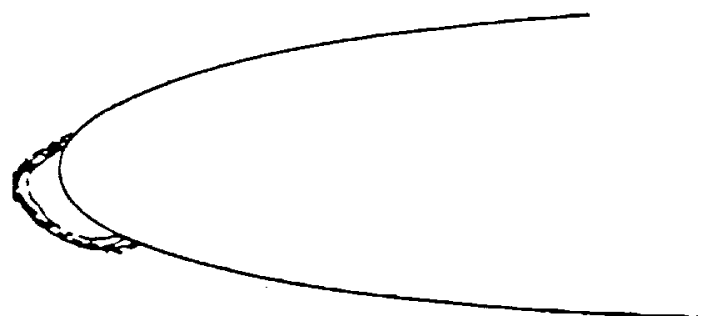

(b) MVO, $12 \mu \mathrm{m}:$ LWC, $1.08 \mathrm{~g} / \mathrm{m}^{3}$ : time, 5 min.

Fig. 3. Repeatability of ice shape and drag for rime ice shapes. Total temperature, $-26^{\circ} \mathrm{C}$; airspeed, $58 \mathrm{~m} / \mathrm{s} ; 0.53 \mathrm{~m}$-chord NACA 0012 airfoil at $4^{\circ}$ (Ref. 9).

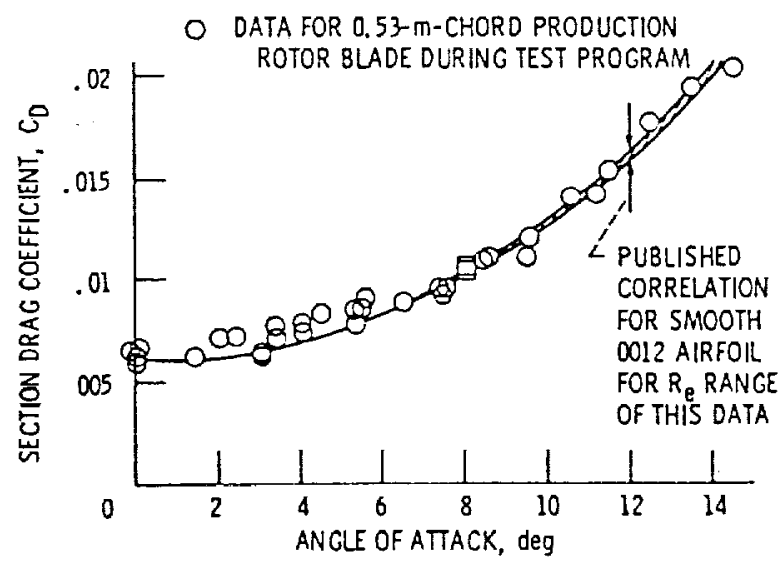

Fig. 4. Comparison of measured clean airfoil data with published data for the NACA 0012 airfoil (Ref. 9). 


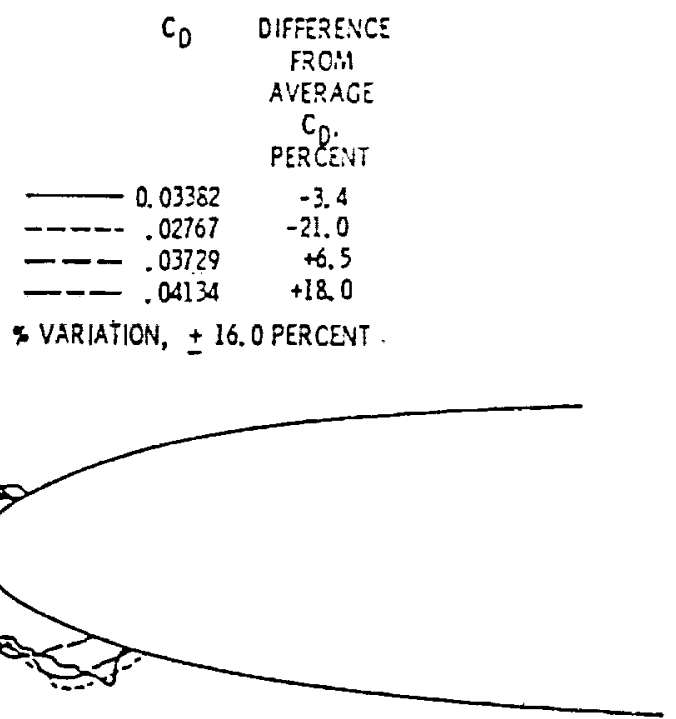

(a) MVD, $20 \mu \mathrm{m}:$ LWC, $2.1 \mathrm{~g} / \mathrm{m}^{3}$ : time, 5 min.
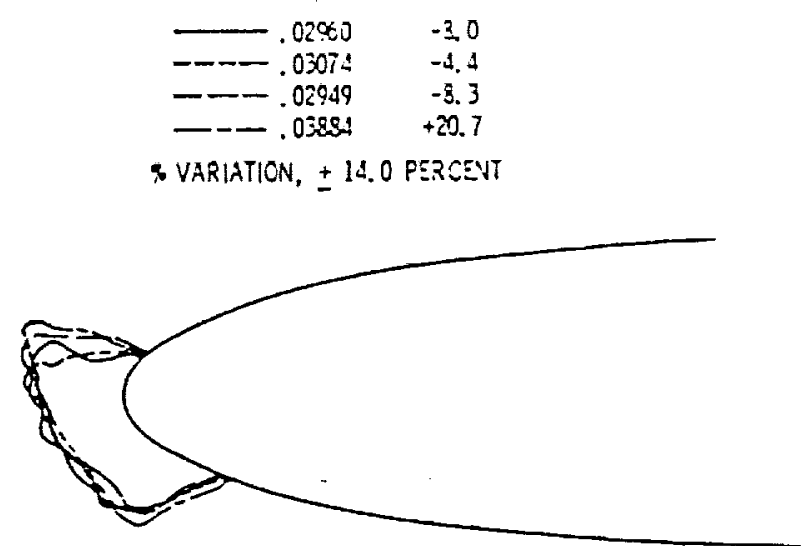

(b) MVO, $20 \mu \mathrm{m}:$ LWC, $1.3 \mathrm{~g} / \mathrm{m}^{3}$ : time, $8 \mathrm{~min}$.

Fig. 5. Repeatability of lce shape and drag for glaze ice shapes. Total temperature, $-8^{\circ} \mathrm{C}$; airspeed, $58 \mathrm{~m} / \mathrm{s} ; 0.53 \mathrm{~m}$-chord NACA 0012 airfoil at $4^{\circ}$ angle (Ref. 9). 


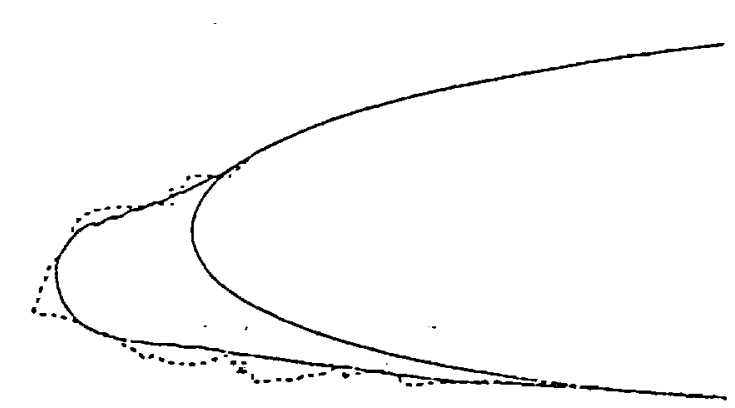

(a)

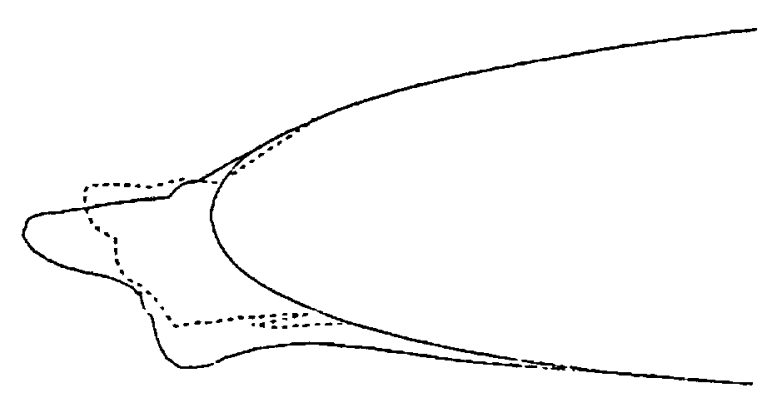

(c)

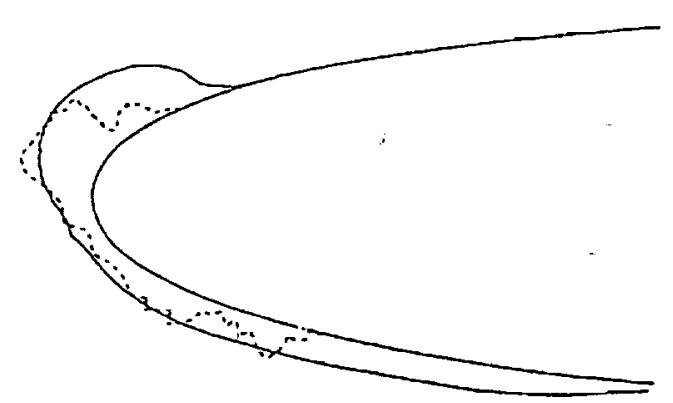

(e)

Fig. 6. Effect of air temperature $T_{S}\left({ }^{\circ} \mathrm{C}\right)$ on ice shapes for fixed droplet size (MVD $=20 \mu \mathrm{m})$, air velocity $\left(V_{\infty}=58 \mathrm{~m} / \mathrm{s}\right)$, liquid water content (LWC $\left.=1.30 \mathrm{~g} / \mathrm{m}^{3}\right):$ (a) $-27.8^{\circ}$, (b) $-19.8^{\circ}$, (c) $-13.9^{\circ}$, (d) $-6.7^{\circ}$, (e) $-3.9^{\circ}$, (f) $-2.8^{\circ}$. All calculations are for $8 \mathrm{~min}$. except for that of (a) which is for 7 min.
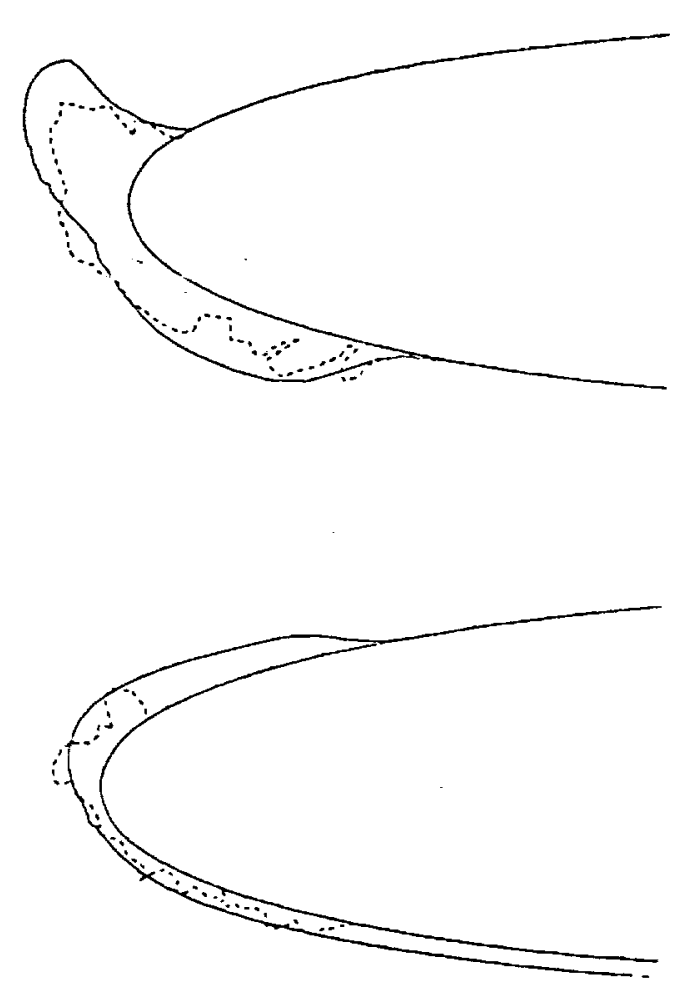

(f)

(d) (b)

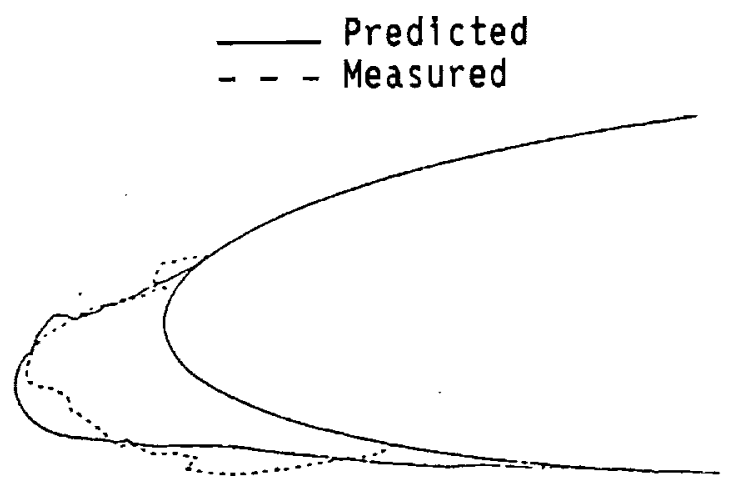




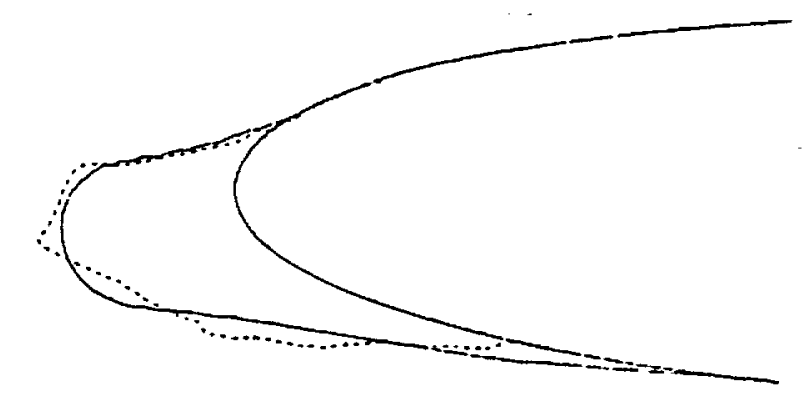

(a)

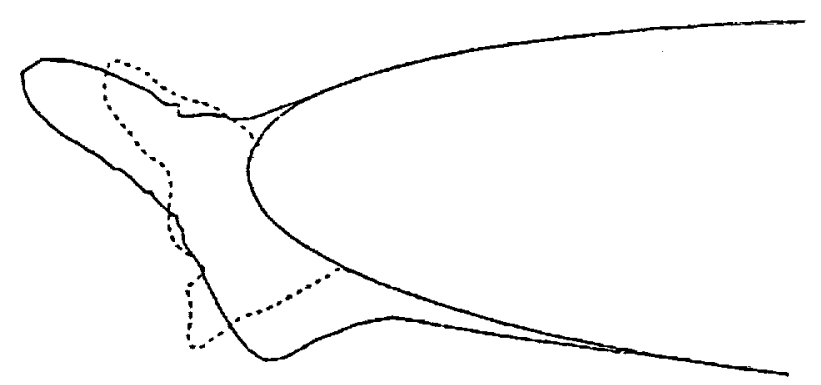

(c)

Fig. 7. Effect of air temperature $T_{S}\left({ }^{\circ} \mathrm{C}\right)$ on ice shapes for fixed droplet size (MVD $=20 \mu \mathrm{m})$, atr velocity $\left(V_{\infty}=94 \mathrm{~m} / \mathrm{s}\right)$, liquid water content ( $\left.L W C=1.05 \mathrm{~g} / \mathrm{m}^{3}\right):$ (a) $-30.5^{\circ}$, (b) $-16.6^{\circ}$, (c) $-12.2^{\circ}$, (d) $-6.6^{\circ}$. All calculations are for $6.2 \mathrm{~min}$. except for that of (d) which is for 4.13 min.

(b)

(d)
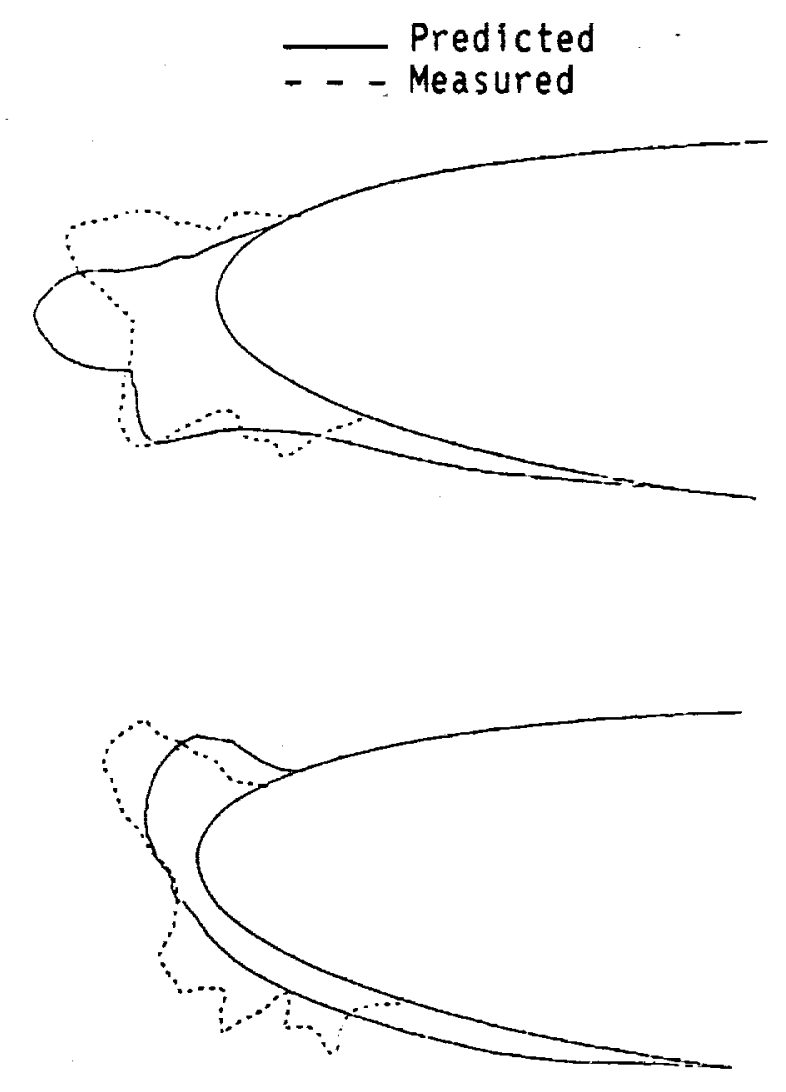


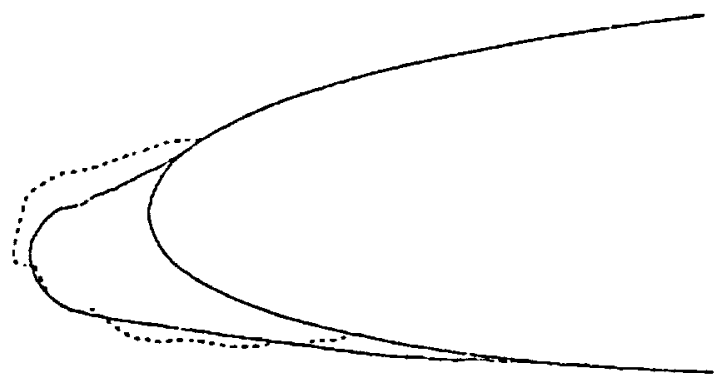

(a)

(b)

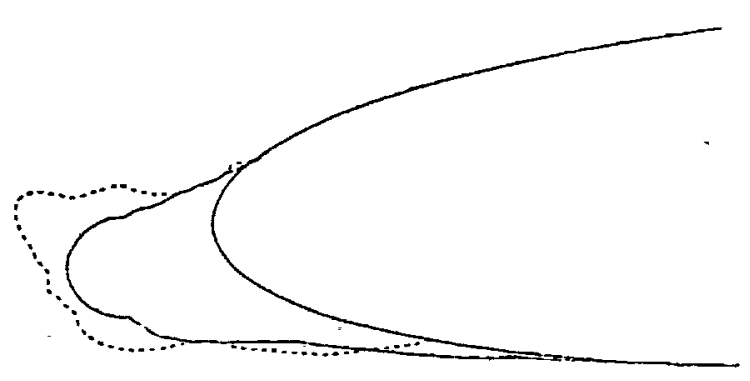

(c)

Fig. 8. Effect of 1 iquid water content, LWC $\left(\mathrm{g} / \mathrm{m}^{3}\right)$; on ice shapes for fixed airspeed $\left(V_{\infty}=58 \mathrm{~m} / \mathrm{s}\right)$, temperature $\left(T_{s}=-19.80^{\circ} \mathrm{C}\right)$, droplet size (MVD $=20 \mu \mathrm{m})$ : (a) 1.0 , (b) 1.3 , (c) 2.0 . All calculations are for $8 \mathrm{~min}$. except for that of (c) which is for $6 \mathrm{~min}$. 


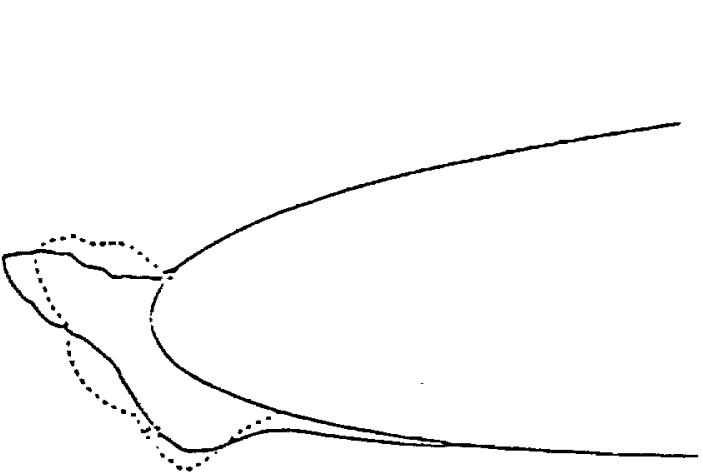

(a)

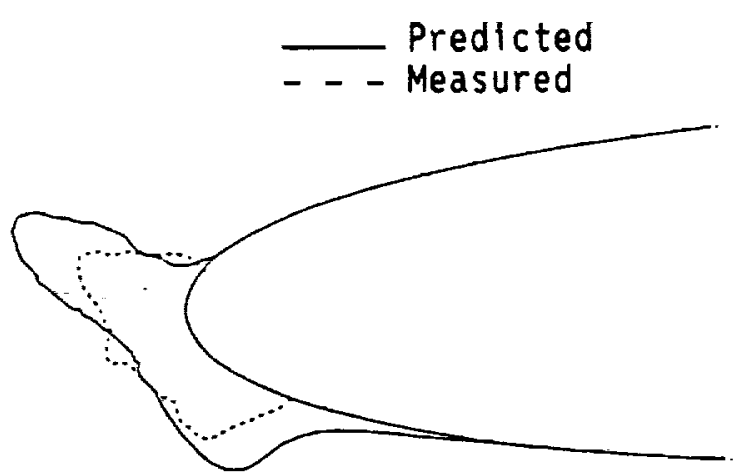

(b)

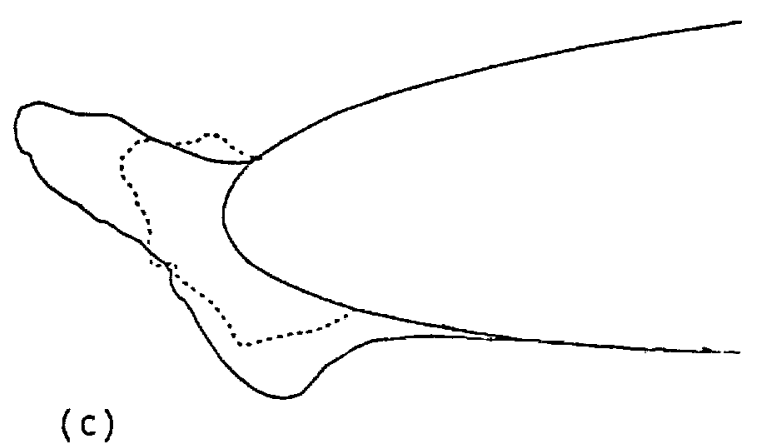

Fig. 9. Effect of liquid water content, $\operatorname{LWC}\left(\mathrm{g} / \mathrm{m}^{3}\right)$, on ice shapes for fixed airspeed $\left(V_{\infty}=58 \mathrm{~m} / \mathrm{s}\right)$, temperature $\left(T_{s}=-9.67^{\circ} \mathrm{C}\right)$, droplet size (MVD $=20 \mu \mathrm{m}):$ (a) 1.0 , (b) 1.3, (c) 1.6. All calculations are for 8 min.

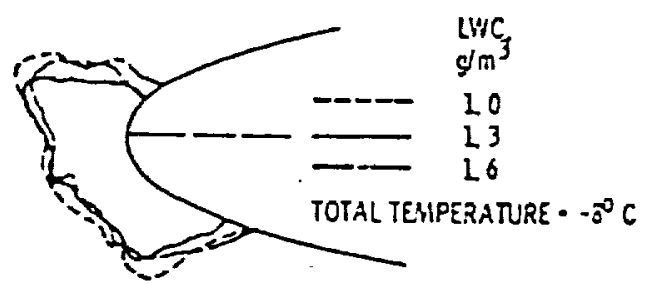

(a)

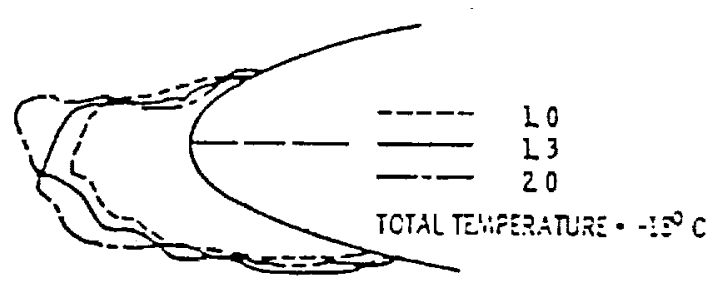

(b)

Fig. 10. Effect of LWC on the ice shape and section drag. Airspeed, $58 \mathrm{~m} / \mathrm{s}$, MVD, $20 \mu \mathrm{m}$; time, $8 \mathrm{~min}$ at $4^{\circ}$ angle of attack (Ref. 9 ). 


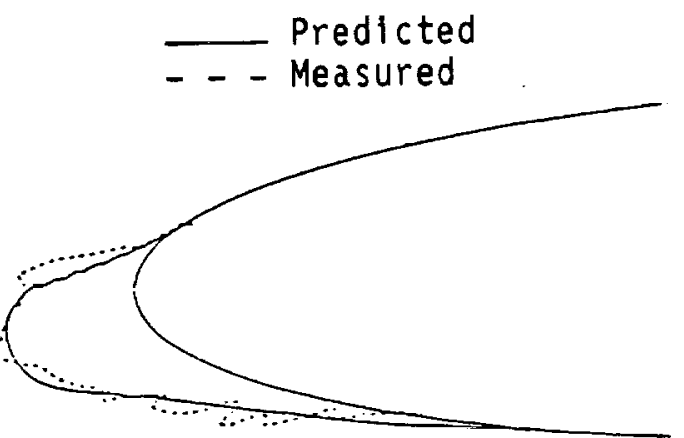

(a)

(b)

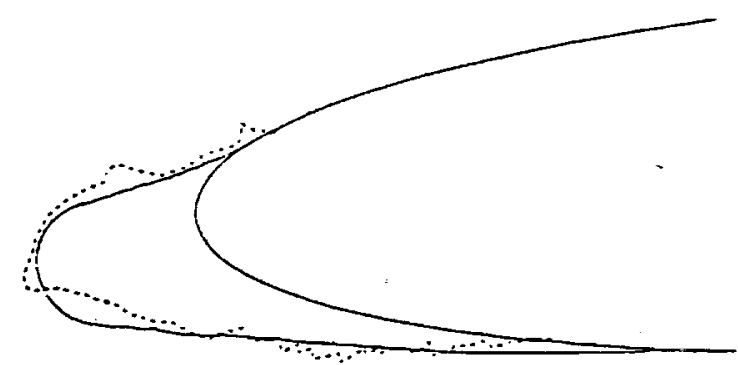

(c)

Fig. 11. Effect of droplet size, MVD $(\mu \mathrm{m})$, on ice shapes for fixed airspeed $\left(V_{\infty}=58 \mathrm{~m} / \mathrm{s}\right)$, temperature $\left(T_{s}=-27.80^{\circ} \mathrm{C}\right.$ ), liquid water content (LWC $=1.30 \mathrm{~g} / \mathrm{m}^{3}$ ): (a) 14 , (b) 20, (c) 26 . Al1 calculations are for 7 min. except for that of (c) which is for $8 \mathrm{~min}$. 


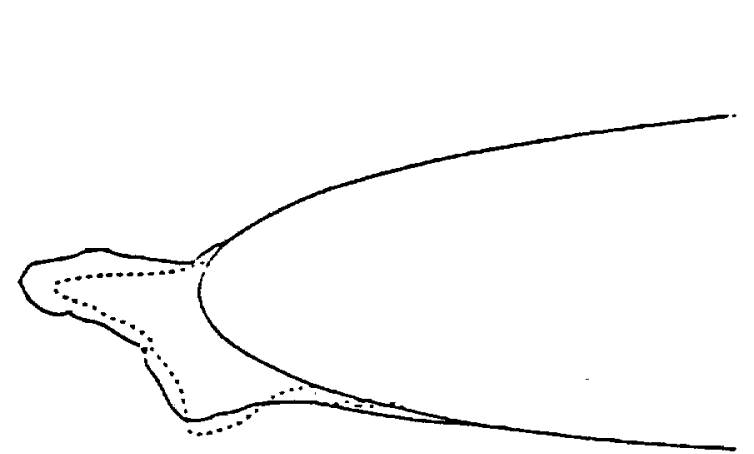

(a)

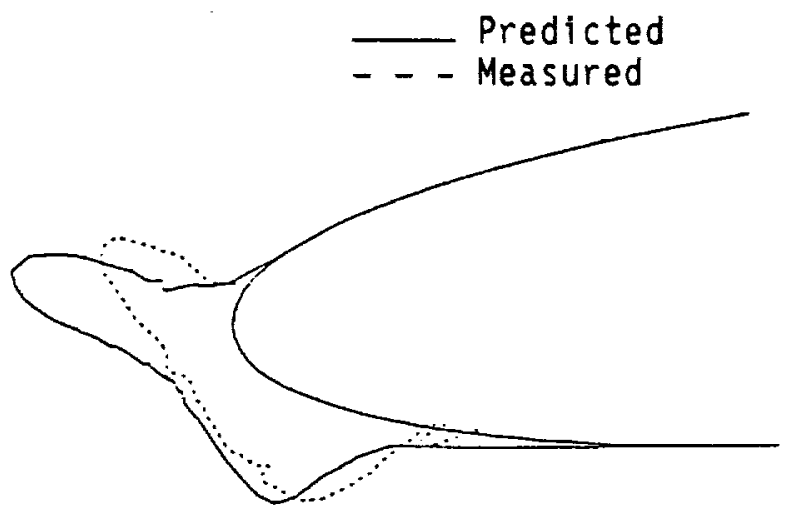

(b)

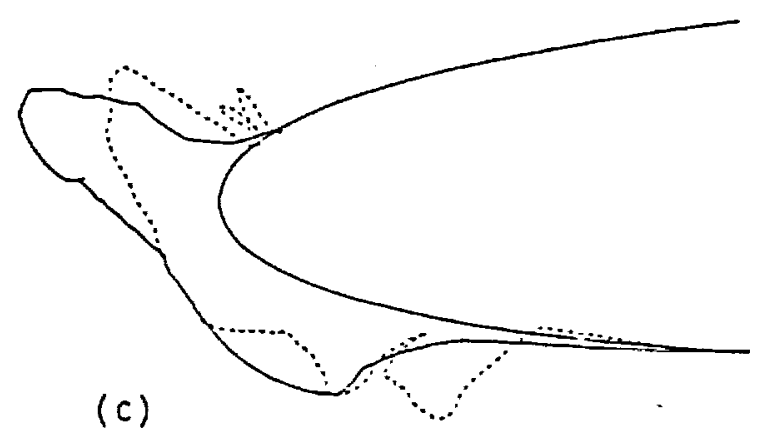

Fig. 12. Effect of droplet size, MVD ( $\mu \mathrm{m})$, on ice shapes for fixed airspeed $\left(V_{\infty}=94 \mathrm{~m} / \mathrm{s}\right)$, temperature $\left(T_{s}=-12.20^{\circ} \mathrm{C}\right)$, liquid water content $\left(\right.$ LWC $\left.=1.05 \mathrm{~g} / \mathrm{m}^{3}\right):$ (a) 14 , (b) 20, (c) 26 . All calculations are for $6.2 \mathrm{~min}$.

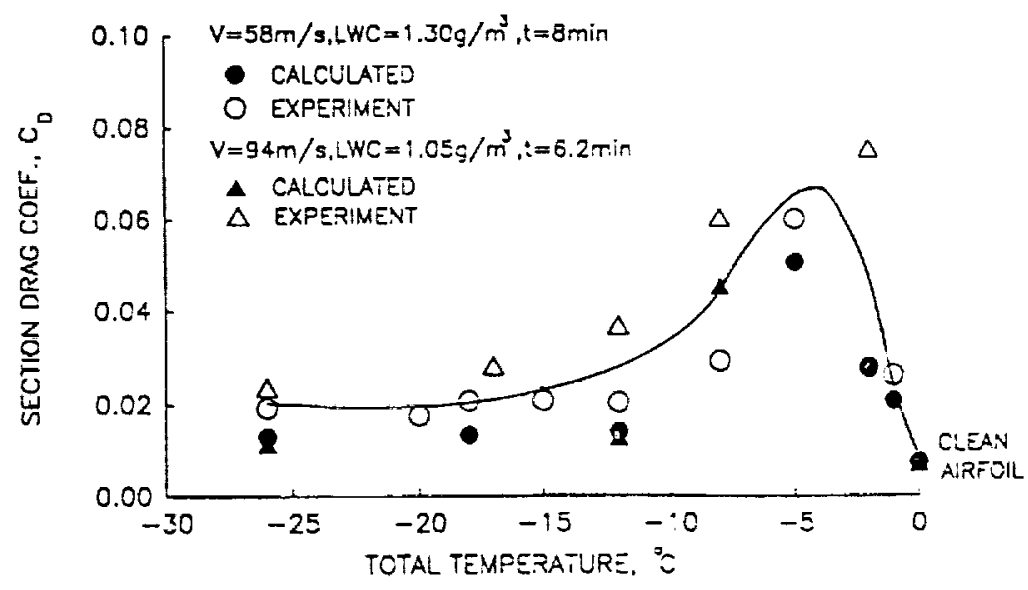

Fig. 13. Variation of the drag coefficient with. total temperature at two air speeds. (Line is a fit for experimental data.) 


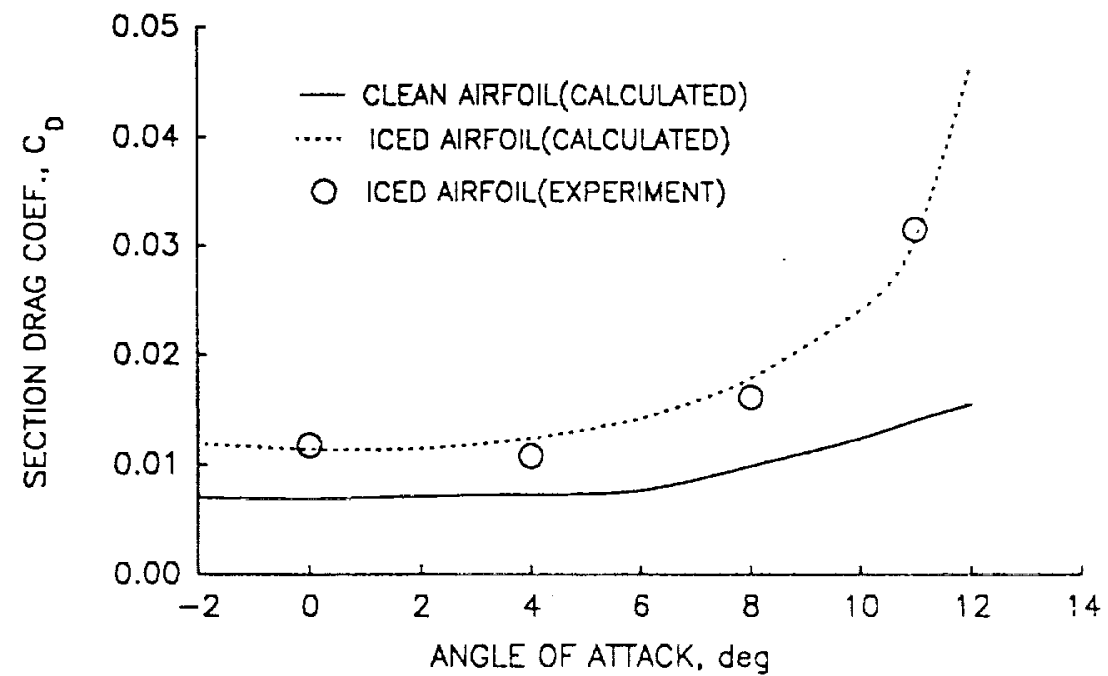

Fig. 14. Variation of the drag coefficient of the airfoll with angle of attack with ice shape determined at $\alpha_{s}=4^{\circ}$ for $V_{\infty}=58 \mathrm{~m} / \mathrm{s}, T_{s}=-27.80^{\circ} \mathrm{C}$, $L W C$ $=1.0 \mathrm{~g} / \mathrm{m}^{3}$, MVD $=12 \mathrm{\mu m}$, ice accretion time $=$ 5 min.

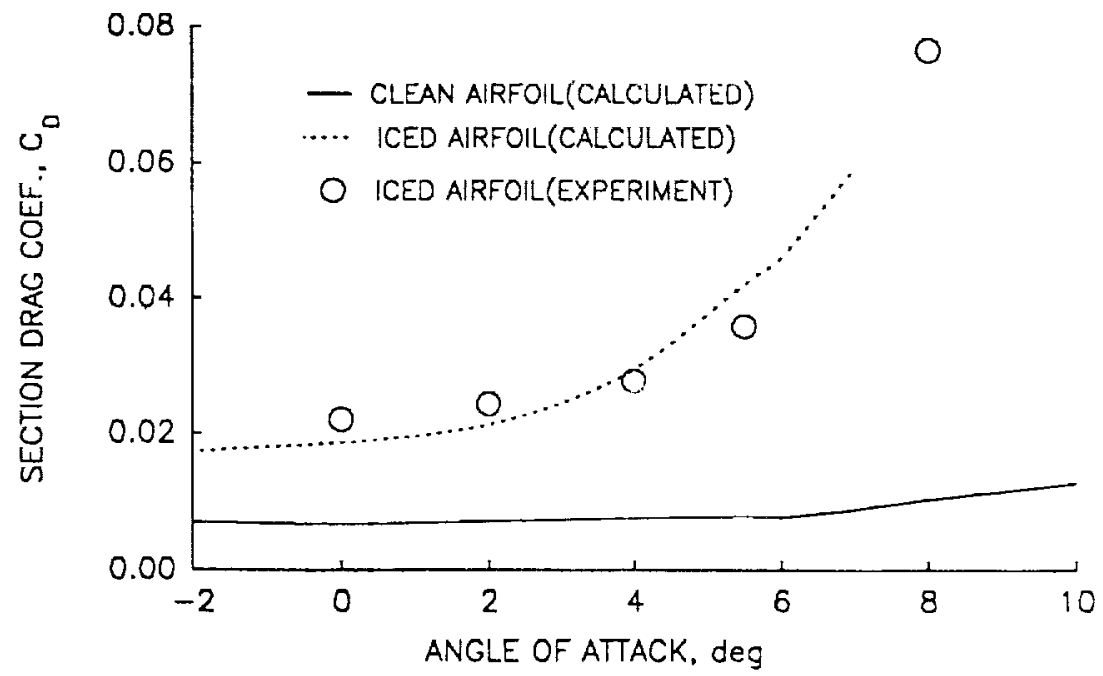

Fig. 15. Variation of drag coefficient of the airfoll with angle of attack with ice shape corresponding to glaze ice determined at $\alpha=4^{\circ}$ for $V_{\infty}=58 \mathrm{~m} / \mathrm{s}, T_{s}=-9.67^{\circ} \mathrm{C}, \quad L W C=1.3 \mathrm{~g} / \mathrm{m}^{3}$, MVD $=20 \mu \mathrm{m}$, ice accretion time $=5 \mathrm{~min}$. 


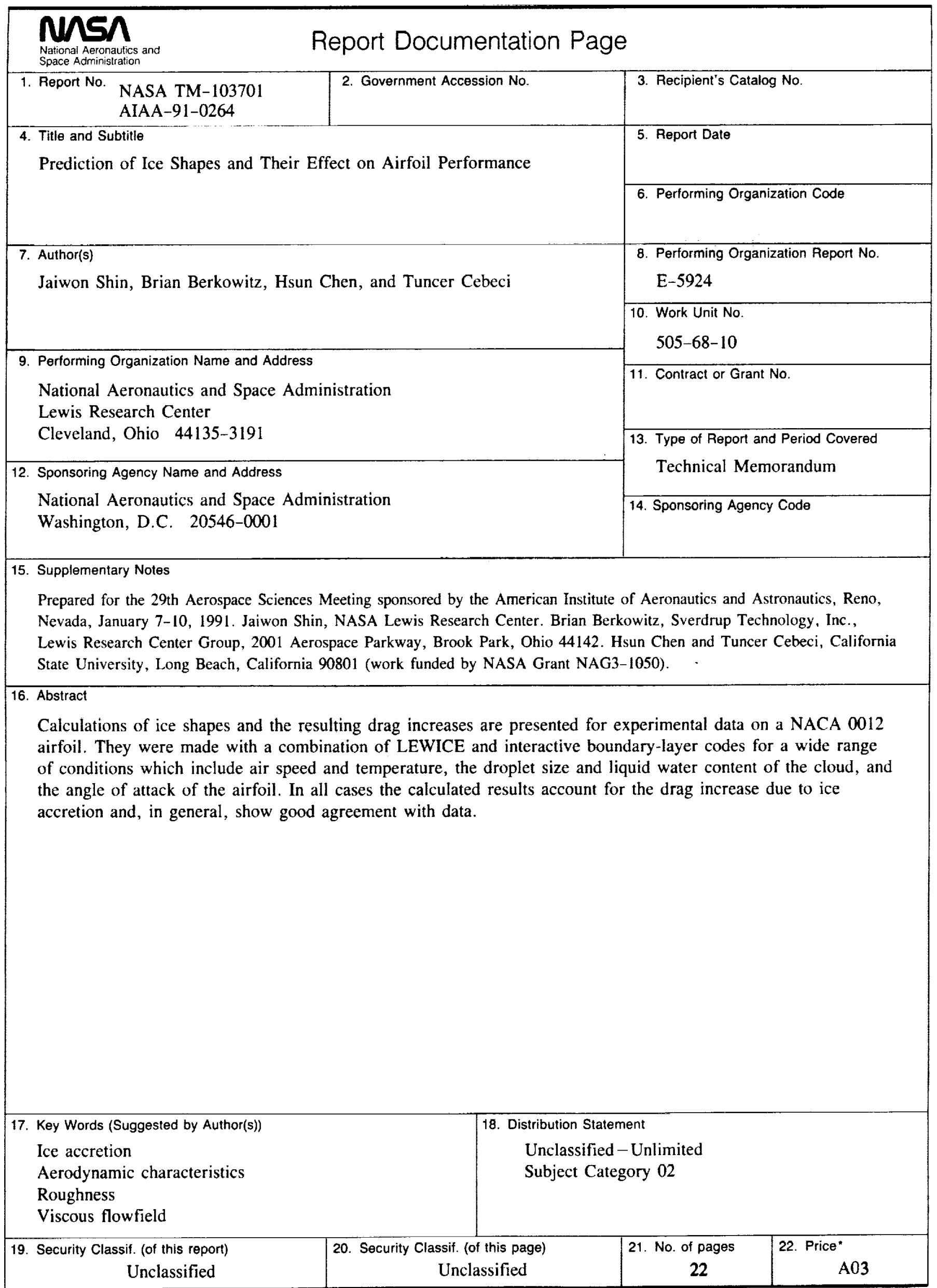

